\title{
ДИЗАЙН И СИНТЕЗ НОВЫХ 5,7- И \\ 6,7-СПИРОЦИКЛИЧЕСКИХ СИСТЕМ ДЛЯ ПОСТРОЕНИЯ НА ИХ ОСНОВЕ БИБЛИОТЕК МАЛЫХ МОЛЕКУЛ
}

\author{
И.Р. Юсупов, А.В. Куркин \\ Московский государственный университет им. М.В. Ломоносова, Москва, Россия, \\ 119991, Ленинские горы, д.1, стр. 3.
}

DOI: 10.19163/MedChemRussia2021-2021-249

E-mail: chemmsuildar@gmail.com

Спироциклические соединения в медицинской химии представлены широким спектром соединений. Благодаря присущей им трехмерности и структурному разнообразию спироциклические фрагменты все чаще используются в поиске лекарственных препаратов [1]. Нами синтезированы новые спиросоединения, содержащие гетероцикл. Каркасом данных соединений являются 7-оксаспиро[4.6] ундец-9-ен (1) и 8-оксаспиро[5.6]додец-10-ен (2). Синтез каркасов включал в себя семь стадий, первые две из которых описаны в литературе. Ключевой стадией получения спироцикла являлась внутримолекулярная реакция метатезиса алкенов. Дальнейшее раскрытие эпоксидов различными нуклеофилами позволяет получить библиотеки соединений с известной и доказанной стереохимией.

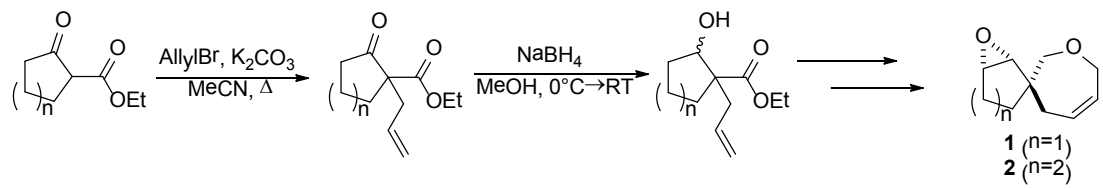

Следующим этапом работы было получение спироцикла с атомом азота в гетероцикле из того же исходного соединения. Полученные производные типа 4 относятся к классу $\gamma$-аминоспиртов. Данный фрагмент встречается как в природных соединениях, так и в лекарственных препаратах [2].<smiles>CCOC(=O)C1CCCCC1=O</smiles>

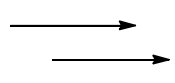<smiles>CC(C)(C)OC(=O)N1CC=CC[C@]2(CCC[C@@H]3O[C@H]32)C1</smiles>

3<smiles>N#[N+][C@@H]1CCC[C@@]2(CC=CCNC2)C1</smiles>

4

Приведенный синтез проводился с использованием простых и доступных реактивов, а общие выходы для соединения 1 составил 37 \%, для 2 - 47 \% и 31 \% для 3 (9 стадий).

Работа выполнена при поддержке гранта РФФИ 20-33-90036.

\section{Литература}

[1] Zheng Y., Tice C. M., Singh S. B. The use of spirocyclic scaffolds in drug discovery. // Bioorg. Med. Chem. Lett. 2014. V.24. P. 3673-3682.

[2] Verkade J. M. M., Quaedflieg P. J. L. M., Verzijl G. K. M., Lefort L., van Delft F. L., de Vries J. G., Rutjes F. P.J.T. Enantio - and diastereoselective synthesis of $\gamma$-amino alcohols. // Chem. Commun. 2015. V.51. P. 14462-14464. 